\title{
Effect of Heparin on Tissue Binding Activity of Fibroblast Growth Factor and Heparin-Binding Epidermal Growth Factor in Experimental Colitis in Rats
}

\author{
ARIE LEVINE, GABRIEL KENET, RAFAEL BRUCK, YONA AVNI, ILANA AVINOACH, \\ HUSSEIN AEED, ZIPPORAH MATAS, MAGDA DAVID, AND AVNER YAYON \\ Pediatric Gastroenterology Service, Division of Gastroenterology [A.L., G.K., R.B., Y.A.], Pathology \\ Institute [I.A.], and Biochemistry and Gastroenterology Laboratory [H.A., Z.M.], E. Wolfson Medical \\ Center, Holon, Israel; Sackler School of Medicine, Tel Aviv University, Tel Aviv, Israel [A.L., G.K., R.B., \\ Y.A., I.A., H.A., Z.M.]; Department of Molecular Cell Biology, Weizmann Institute of Science, Rehovot, \\ Israel [M.D., A.Y.]
}

\begin{abstract}
There have been several reports implying a benefit for heparin therapy in patients with refractory ulcerative colitis. Although this effect has been attributed to the anti-inflammatory properties of heparin, other mechanisms have not been excluded. Heparin is a potent modulator of receptor binding of growth factors such as fibroblast growth factor (FGF), vascular endothelial growth factor, and heparin-binding epidermal growth factor (HB-EGF), that play a role in wound repair. We examined the effect of heparin on the functional levels of FGF and HB-EGF in a model of experimental colitis. Fifty-six Wistar rats were divided into four groups: group 1 was the control group, group 2 received s.c. heparin 50 units $/ \mathrm{kg} / \mathrm{d}$, group 3 underwent induction of $3 \%$ iodoacetamide colitis, and group 4 underwent induction of colitis and heparin treatment. Rats were killed and evaluated for severity of colitis by macroscopic and microscopic colitis scores, area of inflammation, and myeloperoxidase levels. FGF and HB-EGF levels were functionally assessed in colonic tissue in each group. Heparin therapy resulted in significant improvement in macroscopic and microscopic features of colitis $(p<0.05)$, accompanied by a partial reduction in myeloperoxidase levels. FGF receptor binding activity was identical in groups 1 and 2 but increased more than 3-fold after colitis induction in group 3 ( $p<$
\end{abstract}

\section{ABSTRACT}

0.05). Treatment with heparin caused a significant decrease in FGF concentration. Levels of HB-EGF binding activity were similar in groups 1 and 2 and decreased in group $3(p<0.01)$. Heparin caused a significant increase in HB-EGF content in group $4(p<0.05)$. Levels of growth factors are altered differently in experimental colitis. Colonic FGF binding activity increases with colitis, whereas HB-EGF binding decreases with colitis. These trends were reversed by heparin, concomitant with a clinical and pathologic improvement in colitis. We suggest that one mechanism of heparin-mediated improvement in colitis may involve tissue healing associated with changes in functional levels of colonic growth factors. (Pediatr Res 51: 635-640, 2002)
HS, heparan sulfates
FGF, fibroblast growth factor
HBGF, heparin-binding growth factor
HB-EGF, heparin-binding epidermal growth factor
EGF, epidermal growth factor
MPO, myeloperoxidase

\section{Abbreviations}

Since the first report, by Gaffney et al. (1), of the response to heparin in patients with severe ulcerative colitis, there have been conflicting studies regarding its potential use in this setting. Several studies have implied a benefit for heparin therapy for patients with refractory ulcerative colitis (2-7).

Heparin is a polyanionic, highly sulfated, linear polysaccharide belonging to the family of glycosaminoglycans, which

Received July 11, 2001; accepted January 17, 2002.

Correspondence: Arie Levine, M.D., Pediatric Gastroenterology Service, E. Wolfson Medical Center, POB 5, Holon 58100, Israel; e-mail: a-levine@inter.net.il

Supported by a grant from the Sackler School of Medicine, Tel Aviv University. include HS, chondroitin sulfate, hyaluronic acid, dermatan sulfate, keratan sulfate, and heparin. Although most noted for its anticoagulant effect, heparin has a wide range of biologic activities, which include activation of lipoprotein lipase, activation of growth factors, and immune modulation (8-13).

The response of an inflammatory disease to heparin could be theoretically related to a direct effect on the inflammatory response or an improvement in the tissue regenerative capacity. Proposed mechanisms of response have focused mainly on the anti-inflammatory properties of heparin. These involved binding activity of heparin to multiple cytokines, such as IL-2 (8), 

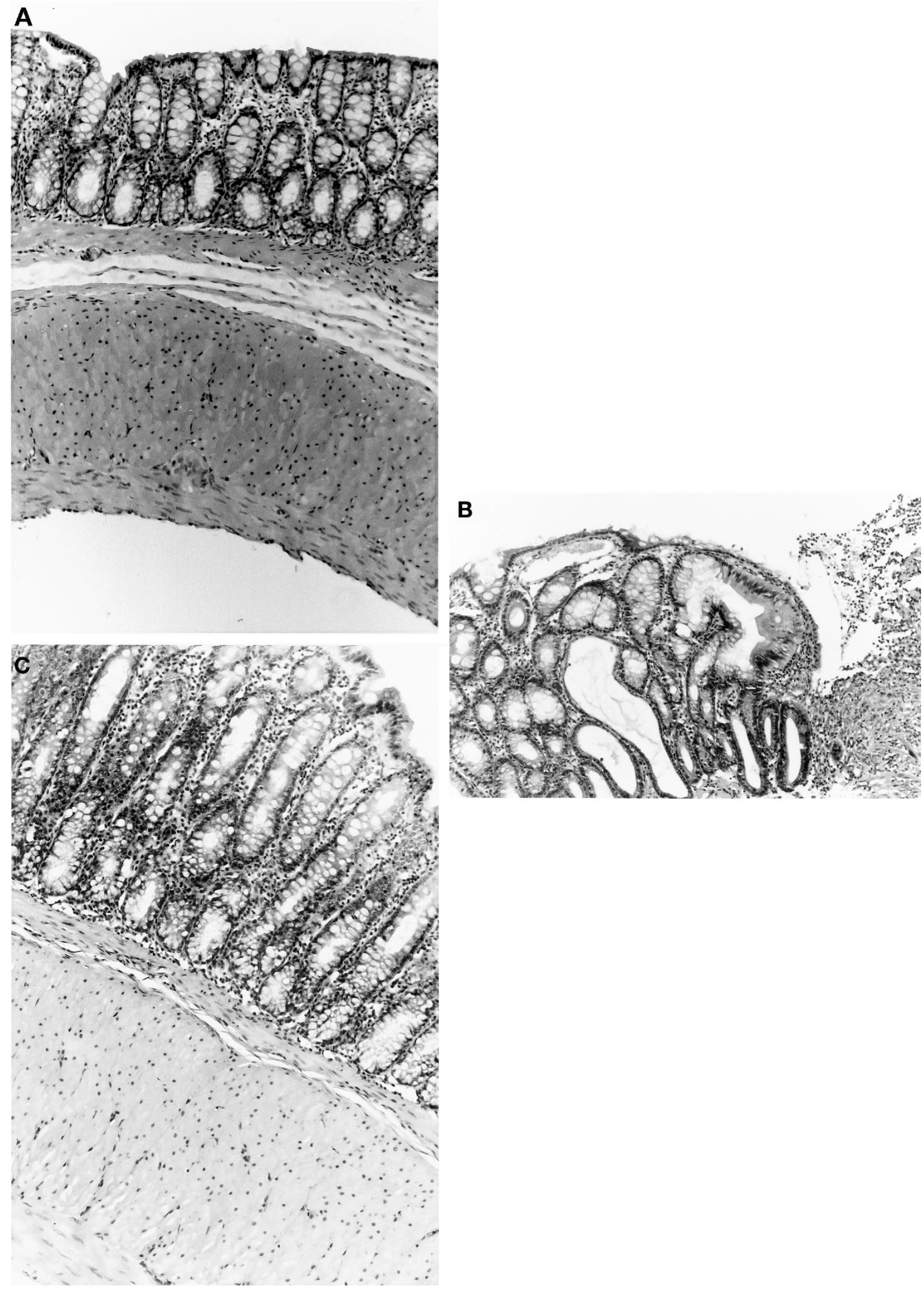

Figure 1. (A) Normal appearance of rat colon (hematoxylin and eosin $\times 100$ ). (B) Microscopic appearance of colitis, untreated (group 3). Focal superficial mucosal ulceration with a mixed inflammatory exudate is seen on the right. The rest of the specimen demonstrates a prominent inflammatory infiltrate in the lamina propria with a crypt abscess (hematoxylin and eosin $\times 200$ ). (C) Microscopic appearance of colitis treated with heparin (group 4). The mucosa and mucosal glands show preserved morphology. A moderate, focally dense infiltrate is present in the lamina propria. The muscular wall and serosa are preserved, without inflammation (hematoxylin and eosin $\times 200$ ). 
interferon- $\gamma(9)$, IL-8, and macrophage chemotactic proteins (10). In addition, Cahalon et al. (11) described a sulfated disaccharide generated through cleavage of heparin by the enzyme heparanase 1, which can inhibit the production of tumor necrosis factor- $\alpha$. Heparin-FGF has been shown to cause down-regulation of class II antigen in a macrophage cellculture model. This effect was independent of FGF (14).

Wound healing could play an important role and serve as one of the mechanisms by which heparin improves colitis. Heparin and HS bind and activate HBGF such as FGF and HB-EGF (12, 13). FGF and HB-EGF are heparin-binding proteins that have an important function in wound healing and angiogenesis. EGF and FGF have both been shown to enable epithelial reconstitution of colonic mucosa in vitro $(15,16)$.

In injured tissue, heparin and specific HS directly enhance the formation of high-affinity FGF-FGF receptor complexes required for biologic activity. Such a mechanism has been found for many other heparin-binding factors, such as vascular endothelial growth factor, hepatocyte growth factor (HGF), and HB-EGF (17), which constitutes a common theme for the local regulation of HBGF activity in vitro and in vivo (18).

Several cell surface HS proteoglycans such as syndecan, fibroglycan, and glypican also possess the ability to inhibit binding of FGF and activation of its receptor. Both activating and inhibitory HS exist, and the balance between them can determine the extent and timing of the response to the associated growth factor in a tissue-specific manner. This inhibitory activity can be competitively reversed by heparin $(19,20)$.

Heparin can also prevent FGF degradation by proteolysis, thus serving as a storage depot and possibly increasing tissue FGF or other HBGF levels and activity in tissue (21-23).

The possible role of growth factors in mediating recovery has been strengthened by a recent study showing that EGF enemas are as effective as mesalamine in colitis (24).

It is therefore important to understand the role that HBGF may play during inflammation, with tissue remodeling, and the possible modulation of these factors by heparin in a model of experimental colitis.

\section{METHODS}

Induction and assessment of experimental colitis. Iodoacetamide colitis was induced as described by Rachmilewitz (25). In short, male Wistar rats were placed on a fast for $24 \mathrm{~h}$. Colitis was induced by the intrarectal administration of $0.2 \mathrm{~mL}$ of 3\% iodoacetamide (Sigma Chemical, St. Louis, MO, U.S.A.) with $1 \%$ methylcellulose (Sigma Chemical). Rats were divided into four groups, 14 rats per group: group 1 was the control group and received sham saline enemas, group 2 received s.c. heparin therapy as an additional control, group 3 underwent iodoacetamide-induced colitis, and group 4 underwent iodoacetamide-induced colitis with heparin therapy. Pilot studies were performed to find the optimal dose of heparin to improve colitis, using doses ranging from 50 to 500 units $(\mathrm{U}) / \mathrm{kg}$ given once daily. Unfractionated heparin (Kamada, Rehovot, Israel) was initiated $24 \mathrm{~h}$ after colitis induction in groups 2 and 4. Rats were injected daily for $7 \mathrm{~d}$, and killed on d 8. Colons were measured and weighed, and areas of inflam- mation were measured (in square centimeters) and assessed macroscopically for inflammation. Samples of colon including areas of inflammation from areas of colitis were snap frozen at $-70^{\circ} \mathrm{C}$ for growth factor analysis. Additional samples from the inflamed and control groups were coded and sent to a pathologist for blinded assessment of microscopic colitis using a scale from 0 to $4(0=$ normal; $1=$ mild mixed inflammatory infiltrates in lamina propria; 2 = focal superficial ulceration of mucosa only, moderate cryptitis, and crypt abscesses; 3 = deep ulceration penetrating colonic wall through muscularis propria and severe inflammation; $4=$ necrosis through large-bowel wall). MPO levels from colonic mucosal scrapings were assessed in a blinded fashion using the technique described by Krawisz et al. (26).

Determination of colonic FGF and HB-EGF content. Functional FGF levels were assayed by a modified method using prepared FGF receptor-1/alkaline phosphatase fusion proteins, as described by Aviezer et al. (19), in duplicates. In brief, samples of colon were mechanically disrupted and lysed and placed in $300 \mu \mathrm{L} 0.15 \mathrm{M} \mathrm{NaCl}$ lysis buffer containing 0.001 M EDTA (BDH, Poole, Dorset, U.K.), 0.05 M Tris, 10\% glycerol, and 1\% NP40 (Sigma Chemical), along with complete protease inhibitor cocktail (Roche Molecular Biochemicals, Mannheim, Germany) for $1 \mathrm{~h}$ on ice. After centrifugation, the resulting supernatant was placed on $50 \mu \mathrm{L}$ heparin Sepharose beads (Pharmacia Biotech, Uppsala, Sweden) for $90 \mathrm{~min}$ at $4^{\circ} \mathrm{C}$ and then centrifuged again. PBS was added to each sample, and samples were centrifuged and divided into aliquots of $25 \mu \mathrm{L}$. FGF receptor-1/alkaline phosphatase and PBS were added to each aliquot of beads and left for $90 \mathrm{~min}$. The supernatant was then set aside. The beads were washed once with $0.5 \mathrm{M} \mathrm{NaCl}$ and then repeatedly with PBS. One hundred microliters alkaline phosphatase substrate (Sigma Chemical) was then added to the beads, which were left for $12 \mathrm{~h}$ and then analyzed at $410 \mathrm{~nm}$ by ELISA reader (TECAN SPECTRA, Mannedorf, Switzerland). Recombinant basic FGF was used as a control for all experiments.

For HB-EGF analysis, supernatant from colon lysis was placed on heparin-coated plates (Carmeda Microtiter Plate, Carmeda AB, Upplands Väsby, Sweden), incubated overnight, and washed extensively to eliminate non-HBGF. BSA $1 \%$ (Sigma Chemical) was added for $1 \mathrm{~h}$ at room temperature and then plates were washed repeatedly with PBS. EGF receptor1-Fc (EGF receptor extracellular domain fixed to human Fc heavy chain, $50 \mathrm{ng} /$ well) was added, incubated for $2 \mathrm{~h}$, and washed with PBS. Protein A horseradish peroxidase (1:5000; Amersham Pharmacia Biotech AB, Uppsala, Sweden), 100 $\mu \mathrm{L} /$ well, was added to the plates, which were then incubated for $2 \mathrm{~h}$ and washed with PBS. Horseradish peroxidase substrate (Sigma Chemical), $100 \mu \mathrm{L} /$ well, was added to the plates, which were then examined on an ELISA reader (TECAN SPECTRA) at $415 \mathrm{~nm}$. Recombinant human HB-EGF was used as a positive control. EGF receptor-1-Fc and human HB-EGF were a generous gift from Yossi Yarden, Weizmann Institute of Science.

This study was approved by an animal use in research committee. 
Table 1. Parameters of colitis severity (mean and SEM)

\begin{tabular}{lcccc}
\hline Weight of & $\begin{array}{c}\text { Area of } \\
\text { inflammation } \\
(\mathrm{cm})\end{array}$ & $\begin{array}{c}\text { Macroscopic } \\
\text { score }\end{array}$ & $\begin{array}{c}\text { Microscopic } \\
\text { score }\end{array}$ \\
\hline I & $0.14 \pm 0.005$ & 0 & 0 & 0 \\
II & $0.12 \pm 0.03$ & 0 & 0 & 0 \\
III & $0.50 \pm 0.17 * *$ & $2.6 \pm 0.78^{* *}$ & $2.4 \pm 0.2 * *$ & $2.7 \pm 0.43^{* *}$ \\
IV & $0.23 \pm 0.03^{*}$ & $1.1 \pm 0.52^{*}$ & $1.3 \pm 0.31 *$ & $0.9 \pm 0.46^{*}$ \\
\hline$* \mathrm{p}<0.05$ groups 3,$4 ; * * \mathrm{p}<0.01$ groups $1,3$.
\end{tabular}

Statistics. Means with upper and lower 95\% confidence limits, SD, and SEM were calculated for parameters of colonic inflammation and severity, and pair-wise analysis was performed using the Mann-Whitney $U$ test, assuming a power of detection of $80 \%$. A $p$ value $<0.05$ was considered significant. Growth factors were assessed across all groups using the Kruskal-Wallis test, and pair-wise analysis was performed using the Mann-Whitney $U$ test.

\section{RESULTS}

Effect of heparin on colitis. During the pilot study, heparin at a dose of $500 \mathrm{U} / \mathrm{kg}$ appeared to cause more severe colitis over a larger area, whereas a dose of $200 \mathrm{U} / \mathrm{kg}$ had no effect. Treatment with heparin at a dose of $50 \mathrm{U} / \mathrm{kg}$ resulted in improvement of colitis. Mean parameters of inflammation were as follows: The areas of inflammation measured for colitis groups treated with heparin $50 \mathrm{U} / \mathrm{kg}, 200 \mathrm{U} / \mathrm{kg}$, or $500 \mathrm{U} / \mathrm{kg}$ were $1.8,1.9$, and $3.6 \mathrm{~cm}^{2}$, respectively $(p<0.05$ for 500 $\mathrm{U} / \mathrm{kg}$ ). Severity scores for colitis groups treated with heparin $50 \mathrm{U} / \mathrm{kg}, 200 \mathrm{U} / \mathrm{kg}$, or $500 \mathrm{U} / \mathrm{kg}$ were $2.39,2.3$, and 3.0 (NS), and weight/area of colon was $0.13,0.27$, and $0.44 \mathrm{~g} / \mathrm{cm}(p=$ 0.06 ), respectively. HBGF analysis was not performed in this group. The study was then repeated, using heparin at a dose of $50 \mathrm{U} / \mathrm{kg} / \mathrm{rat}$ with 14 rats in each of the four groups. After the rats were killed, mean weights were similar for controls and groups 1 and $2(470.5 \pm 57 \mathrm{~g}$ versus $460.7 \pm 18 \mathrm{~g}$, respectively) and significantly higher than weights in groups 3 and 4 (274.2 $\pm 27 \mathrm{~g}$ versus $282 \pm 41 \mathrm{~g}$, respectively, $p<0.05)$. Heparin therapy resulted in decreased severity of colitis (Fig. 1). Parameters of severity of inflammation such as colonic weight $/ \mathrm{cm}^{2}$ colon, area of inflammation, severity of macroscopic inflammation, and microscopic colitis score were all significantly higher in the colitis group in comparison with the colitis group treated with heparin (Table 1) and groups 1 and 2 . MPO levels increased significantly in group 3 in comparison with the control groups $(0.88 \pm 0.73 \mathrm{U} / \mathrm{g}$ versus $0.22 \pm 0.06$ $\mathrm{U} / \mathrm{g}$ wet tissue, $p<0.05$ ), and although there was a $50 \%$ decrease in mean MPO levels with heparin treatment $(0.40 \pm$ $0.46 \mathrm{U} / \mathrm{g}$ wet tissue), this did not attain statistical significance, possibly due to sample size.

Effect of heparin on functional levels of growth factors. Tissue binding activity levels of FGF and HB-EGF are depicted in Figures 2 and 3. The elevation in FGF binding activity during colitis was statistically significant $(p<0.05)$ in comparison with the other three groups. FGF levels, expressed as means and SEM in groups 1 through 4 were $10.86 \pm 2.44$, $10.93 \pm 0.4,35.69 \pm 7.3$, and $10.53 \pm 1.8 \mathrm{ng} / \mathrm{mg}$ protein,

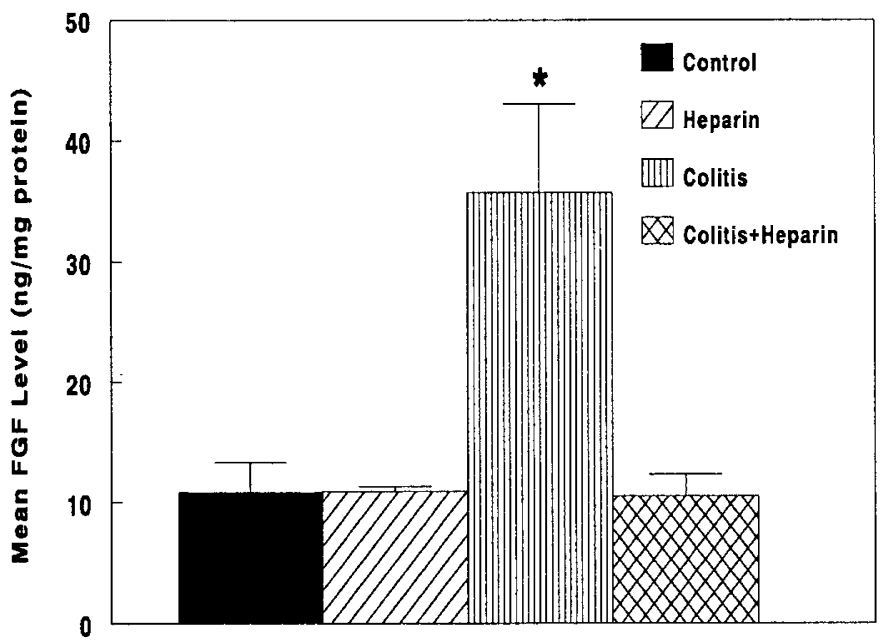

Figure 2. Mean tissue FGF binding activity and response to heparin therapy. $* p<0.05$.

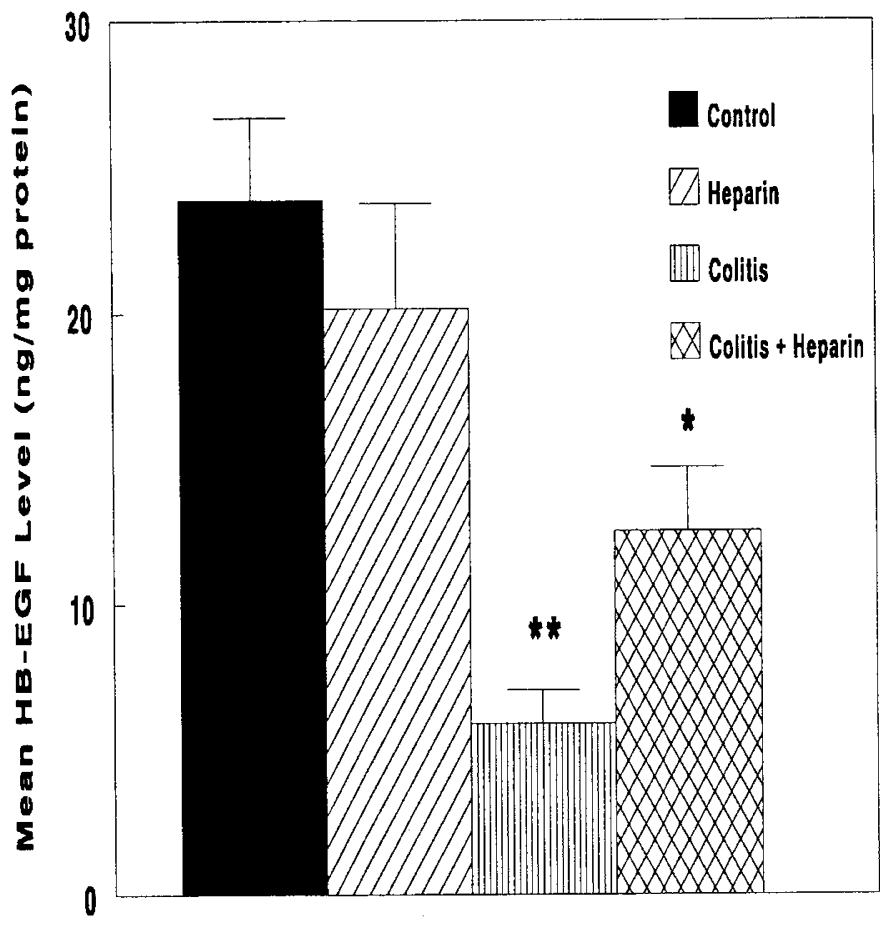

Figure 3. Mean tissue HB-EGF-like binding and response to heparin therapy. $* p<0.05, * * p<0.01$.

respectively. Tissue HB-EGF during colitis was significantly depressed in comparison with the other three groups, $p<0.01$ in comparison with groups 1 and 2 , and $p<0.05$ in comparison with group 4. HB-EGF equivalents (mean and SEM) for groups 1 through 4 were $23.88 \pm 2.8,20.18 \pm 3.59,5.9 \pm$ 1.15 , and $12.37 \pm 2.1 \mathrm{ng} / \mathrm{mg}$ protein, respectively.

\section{DISCUSSION}

In our study, tissue FGF binding activity was significantly increased, more than 3-fold, in the colitis group, and almost identical in the three other groups. Although we cannot discriminate at this stage which of the FGF receptor-1 binding members of the FGF family was specifically altered, treatment 
of colitis with heparin caused a decrease in total tissue FGF binding activity to normal levels. This result could be due to a direct effect of heparin on protein or receptor binding activity of FGF or an indirect effect on these parameters attributed to tissue recovery, with normalization of FGF activity. The identical levels of FGF activity in groups 1and 2 indicate that this effect is not due to a heparin-mediated change in binding to heparin Sepharose beads.

The therapeutic effect of heparin in experimental colitis has been previously shown in both iodoacetamide- and trinitrobenzensulfonic (TNBS)-induced colitis (27). Our rats were killed on d 8. Rachmilewitz et al. (25), in the same model, demonstrated that peak inflammation was achieved between $\mathrm{d} 3$ and 7 , and that recovery time in untreated rats was $3 \mathrm{wk}$. Mucosal regeneration was noted after $2 \mathrm{wk}$ of inflammation. Thus, $1 \mathrm{wk}$ after induction of colitis, at peak inflammation and before full recovery, would seem to be the ideal time to associate changes in HBGF levels with a therapeutic agent, as opposed to recovery from spontaneous tissue regeneration. Furthermore, the heparin-treated group still had significant inflammation present, although HBGF levels were significantly altered. The kinetics of our study may therefore suggest a direct effect of heparin on HBGF levels, including a decrease in total FGF levels with treatment.

Total tissue FGF activity was decreased in the healing phase associated with heparin therapy. If FGF accelerates tissue recovery and healing from inflammation, the drop in tissue levels during therapy and recuperation would be an unlikely reason for recovery. An alternative, although less likely, possibility is that heparin may have improved colitis by decreasing tissue FGF levels. If a HBGF has a deleterious effect on inflammation, decreasing certain HBGF levels could mediate recovery. Byrd et al. (28) demonstrated that FGF-1 stimulation of $\mathrm{T}$ cells expressing receptors for FGF-1 augmented IL-2 production through FGF-1 activation of nuclear factor- $\kappa \mathrm{B}$. Thus, decreasing FGF tissue levels might attenuate inflammation while still enabling augmentation of mechanisms leading to tissue proliferation and differentiation. The similar levels in the heparin-treated control and normal control groups (groups 1 and 2) make a direct effect of heparin therapy on tissue binding activity of FGF less likely, although the effect of heparin may differ during inflammation.

Our data regarding increased FGF binding activity during colitis are supported indirectly by the findings of Bousvaros et al. (29), who found increased serum FGF in pediatric patients with inflammatory bowel disease, which parallels disease activity. To our knowledge, FGF has not been quantitatively assessed in inflamed colonic tissue from patients with inflammatory bowel disease, although Ohtani et al. (30) described increased immunocytochemical staining for FGF in inflammatory exudates in comparison with colonic tissue from control samples. Our results, demonstrating a decrease in FGF with heparin, contrast with those published in an experimental ulcer model using a similar compound (acetic acid), in which both tissue FGF and EGF levels increased after heparin therapy. Doses of 100,500 , and $1000 \mathrm{U} / \mathrm{kg}$ were used, and response occurred in a dose-dependent fashion, resulting in healing (21). These opposite interactions may be explained by the presence of inflammation in our model, which appears to be a potent stimulus for FGF. Tissue HB-EGF responded differently than FGF to heparin therapy. HB-EGF binding activity was significantly decreased in the colitis group, and increased significantly with heparin therapy, although the levels measured were well below the normal values. EGF has been found to have a direct beneficial effect on colitis (24), and the increase in HB-EGF may have played a role in tissue recovery that we observed. The same arguments put forth previously for cause and effect are relevant here as well. The increased binding activity of this growth factor in the treatment group (group 4), suggests a role for heparin in growth factor-mediated response. Epithelial damage in colitis may have caused a decrease in epithelial HB-EGF, leading to decreased HB-EGF binding activity that we measured in the colitis group.

There are other heparin-growth factor interactions that may play a role in colitis and explain a response to heparin therapy. HS, which bind FGF, appear to be depleted in areas of inflammation in inflammatory bowel disease $(23,31)$. This could lead to decreased tissue binding of HBGF and decreased HBGF activity in areas of inflammation. Other HBGF implicated in colitis, such as vascular endothelial growth factor, were not evaluated.

The dose-response curve in our pilot studies, with a lower dose being efficacious and a high dose detrimental, is of interest. Assuming a purely anti-inflammatory role for heparin based on binding of pro-inflammatory cytokines, or an increase in HS barrier function, increasing the heparin dose would be expected to decrease inflammation in a dose-related fashion.

A low-dose effect could support a role for a direct increase in HBGF activity as a mechanism of response. At low tissue levels, optimal heparin levels required for the formation of an active ternary complex can bind to both a HBGF and its receptor, facilitating growth factor activity. Because heparin acts as a ligand to HBGF, higher doses, in excess of tissue receptor levels needed for growth factor activity, might have a competitive effect and actually reduce tissue levels by binding circulating beneficial HBGF. This could decrease the potential for recovery, leading to aggravation of colitis at higher doses $(27,32)$. We did not evaluate HBGF levels or binding activity at the higher doses.

An alternative explanation for a low-dose response has been proposed by Lider, Cahalon, and colleagues $(11,33)$. They found that low-dose heparin inhibits T-cell heparanase, and prevents T-cell migration toward antigen, in an animal model of inflammation. This effect was abolished by lower or higher doses of heparin. Variation in tissue levels of heparin may be responsible for different results achieved during therapy of ulcerative colitis. In theory, heparin may have a narrow therapeutic margin, which should not be exceeded. High-dose heparin may have decreased clinical potential with a higher risk for side effects. The effect achieved with use of low-dose versus high-dose heparin in patients with ulcerative colitis needs to be evaluated in clinical trials.

In conclusion, experimental colitis affects HBGF in different ways. Resolution with heparin therapy led to near or complete normalization of HBGF binding activity, elevating HB-EGF and decreasing FGF receptor binding activity. Although 
changes in HBGF may play a role in recovery from colitis, kinetic studies of HBGF during early inflammation may help to clarify the interaction between HBGF, heparin therapy, and colitis and may further elucidate the role that heparin might play in the treatment of inflammatory diseases. The optimal dose of heparin needs to be evaluated in clinical trials.

\section{REFERENCES}

1. Gaffney PR, O’Leary JJ, Doyle CT, Gaffney A, Hogan J, Smew F, Annis P 1991 Response to heparin in patients with ulcerative colitis. Lancet 337:238-239

2. Gaffney PR, Doyle CT, Gaffney A, Hogan J, Hayes DP, Annis P 1995 Paradoxical response to heparin in 10 patients with ulcerative colitis. Am J Gastroenterol 90:220-223

3. Dwarakanath AD, Yu LG, Brookes C, Pryce D, Rhodes JM 1995 'Sticky' neutrophils, pathergic arthritis, and response to heparin in pyoderma gangrenosum complicating ulcerative colitis. Gut 37:585-588

4. Evans RC, Wong VS, Morris AI, Rhodes JM 1997 Treatment of corticosteroidresistant ulcerative colitis with heparin - a report of 16 cases. Aliment Pharmacol Ther 11:1037-1040

5. Folwaczny C, Wiebecke B, Loeschke K 1999 Unfractioned heparin in the therapy of patients with highly active inflammatory bowel disease. Am J Gastroenterol 94:15511555

6. Ang YS, Mahmud N, White B, Byrne M, Kelly A, Lawler M, McDonald G, Smith O, Keeling P 2000 Randomized comparison of unfractionated heparin with corticosteroids in severe active inflammatory bowel disease. Aliment Pharmacol Ther 14:10151022

7. Panes J, Esteve M, Cabre E, Hinojosa J, Andreu M, Sans M, Fernandez-Banares F, Feu F, Pique JM 2000 Comparison of heparin and steroids in the treatment of moderate and severe ulcerative colitis. Gastroenterology 119:903-908

8. Najjam S, Gibbs RV, Gordon MY, Rider CC 1997 Characterization of human recombinant interleukin 2 binding to heparin and heparan sulfate using an ELISA approach. Cytokine 9:1013-1022

9. Douglas MS, Rix DA, Dark JH, Talbot D, Kirby JA 1997 Examination of the mechanism by which heparin antagonizes activation of a model endothelium by interferon-gamma (IFN-gamma). Clin Exp Immunol 107:578-584

10. Jackson DG 1997 Human leucocyte heparan sulphate proteoglycans and their roles in inflammation. Biochem Soc Trans 25:220-224

11. Cahalon L, Lider O, Schor H, Avron A, Gilat D, Hershkovitz R, Margalit R, Eshel A, Shoseyev O, Cohen IR 1997 Heparin disaccharides inhibit tumor necrosis factoralpha production by macrophages and arrest immune inflammation in rodents. Int Immunol 10:1517-1522

12. Yayon A, Klagsbrun M, Esko J, Leder P, Ornitz D 1991 Cell surface heparin-like molecules are required for binding basic fibroblast growth factor to its high affinity receptor. Cell 64:841-848

13. Aviezer D, Yayon A 1994 Heparin-dependent binding and autophosphorylation of epidermal growth factor (EGF) receptor by heparin-binding EGF-like growth factor but not by EGF. Proc Natl Acad Sci USA 91:12173-12177

14. Hackshaw KV, Lakshmanan RR, Everett RW, Fox CC 1998 Downregulation of class II antigen expression by FGF-heparin complexes is due primarily to heparin effect. Res Commun Mol Pathol Pharmacol 101:99-114
15. Riegler M, Sedivy R, Sogukoglu T, Cosentini E, Bischof G, Teleky B, Feil W, Schiessel R, Hamilton G, Wenzl E 1997 Effect of growth factors on epithelial restitution of human colonic mucosa in vitro. Scand J Gastroenterol 32:925-932

16. Dignass AU, Tsunekawa S, Podolsky DK 1994 Fibroblast growth factors modulate intestinal epithelial cell growth and migration. Gastroenterology 106:1254-1262

17. Ono K, Hattori H, Takeshita S, Kurita A, Ishihara M 1999 Structural features in heparin that interact with VEGF165 and modulate its biological activity. Glycobiology 9:705-711

18. Aviezer D, Hecht D, Safran M, Yayon A 1994 Perlecan, basal lamina proteoglycan, promotes basic fibroblast growth factor-receptor binding, mitogenesis, and angiogenesis. Cell 79:1005-1013

19. Aviezer D, Levy E, Safran M, Svahn C, Buddecke E, Schmidt A, David G, Vlodavsky I 1994 Differential structural requirements of heparin and heparan sulfate proteoglycans that promote binding of basic fibroblast growth factor to its receptor. J Biol Chem 269:114-121

20. Guimond S, Maccarana M, Olwin BB, Lindahl U, Rapraeger A 1993 Activating and inhibitory heparin sequences for FGF-2 (basic FGF). Distinct requirements for FGF-1, FGF-2, and FGF-4. J Biol Chem 268:23906-23914

21. Li Y, Wang HY, Cho CH 1999 Association of heparin with basic fibroblast growth factor, epidermal growth factor, and constitutive nitric oxide synthase on healing of gastric ulcer in rats. J Pharmacol Exp Ther 290:789-796

22. Saksela O, Moscatelli D, Sommer A, Rifkin DB 1988 Endothelial cell-derived heparan sulfate binds basic fibroblast growth factor and protects it from proteolytic degradation. J Cell Biol 107:743-751

23. Day R, Forbes A 1999 Heparin, cell adhesion, and pathogenesis of inflammatory bowel disease. Lancet 354:62-65

24. Sinha A, Nightingale J, West K, Berlanga-Acosta J, Playford E 2001 Epidermal growth factor enemas are effective in the treatment of left sided ulcerative colitis. Gastroenterology 120(suppl 1):A11

25. Rachmilewitz D, Karmeli F, Okon E 1995 Sulfhydryl blocker-induced rat colonic inflammation is ameliorated by inhibition of nitric oxide synthase. Gastroenterology 109:98-106

26. Krawisz JE, Sharon P, Stenson WF 1984 Quantitative assay for acute intestinal inflammation based on myeloperoxidase. Gastroenterology 87:1344-1350

27. Dotan I, Hershkoviz R, Karmeli F, Brazowski E, Peled Y, Rachmilewitz D, Halpern Z 2001 Heparin and low-molecular-weight heparin (enoxaparin) significantly ameliorate experimental colitis in rats. Aliment Pharmacol Ther 15:1687-1697

28. Byrd VM, Ballard DW, Miller GG, Thomas JW 1999 Fibroblast growth factor-1 (FGF1) enhances IL-2 production and nuclear translocation of NF-kappaB in FGF receptor bearing Jurkat T cells. J Immunol 15:5853-5859

29. Bousvaros A, Zurakowski D, Fishman SJ, Keough K, Law T, Sun C, Leichtner AM 1997 Serum basic fibroblast growth factor in pediatric Crohn's disease. Implications for wound healing. Dig Dis Sci 42:378-386

30. Ohtani H, Nakamura S, Watanabe Y, Mizoi T, Saku T, Nagura H 1993 Immunocytochemical localization of basic fibroblast growth factor in carcinomas and inflammatory lesions of the human digestive tract. Lab Invest 68:520-527

31. Murch S, MacDonald T, Walker-Smith J, Levin M, Lionetti P, Klein N 1993 Disruption of sulphated glycosaminoglycans in intestinal inflammation. Lancet 341:711-714

32. Park M, Taek-Lee S 1999 The fourth immunoglobulin-like loop in the extracellular domain of FLT-1, a VEGF receptor, includes a major heparin-binding site. Biochem Biophys Res Comun 264:730-734

33. Lider O, Cahalon L, Gilat D, Hershkoviz R, Siegel D, Margalit R, Shoseyov O, Cohen IR 1995 A disaccharide that inhibits tumor necrosis factor alpha is formed from the extracellular matrix by the enzyme heparanase. Proc Natl Acad Sci U S A 92:50375041 